\title{
ABDOMINAL TUBERCULOSIS;
}

STILL THE GREAT MIMICKER

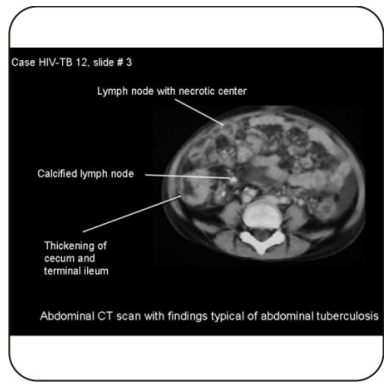

DR. SHEIKH ATIQ-UR-REHMAN, FCPS

Senior Registrar surgical unit II

B-V Hospital Bahawalpur

DR. GULZAR AHMED, FCPS

Professor of Surgery, surgical unit IV

B-V Hospital Bahawalpur
DR. AHMED YAR, FCPS

Registrar surgical unit II

B-V Hospital Bahawalpur

ABSTRACT...Objectives: To study the different clinical presentations, operative and postoperative course of abdominal tuberculosis. Design: Case series study. Setting: Surgical units, Bahawal Vicotria Hospital, Bahawalpur . Period: May 01, 2005 to April 30, 2007. Patients \& Method: This was a prospective type of case series study. A selection criterion of patients was that all patients of either sex \& age being diagnosed as case of abdominal tuberculosis. The clinical record of the patient's data, symptoms \& signs, biopsy report, biochemical \& radiological report, treatment (surgery \& chemotherapy) given and a follow-up. Results: Total 96 patients presented with abdominal tuberculosis, 60(62.5\%) were male \& $36(37.5 \%)$ were female. Peritonitis was present in $48(50 \%)$ patients, intestinal obstruction(acute \& sub-acute) was present in 32(33.33\%) patients, mass right iliac fossa was present in 14(14.58\%) patients and 2(2.08\%) patient presented with mass in the epigastrium. $28(29.16 \%)$ patients has concurrent pulmonary tuberculosis. Two patients expired so mortality rate was $2.08 \%$. Conclusion: The control of TB has been a challenging problem because the natural history of the disease and its varying pattern in which it manifests is in different groups.

Key words: Mycobacterial infection in gastrointestinal tract, koch infection, Gastrointestinal tuberculosis, Mycobacterium tuberculosis.

\section{INTRODUCTION}

Each year, tuberculosis (TB) results in the death of 3 million people globally. In 2000-2020, an estimated 1 billion people will be infected, 200 million people will become sick, and 35 million will die from TB, if control is not strengthened. An estimated 10-15 million people are infected with M. tuberculosis. Only $4 \%$ of persons with HIV develop TB. In persons co infected with TB and HIV, the risk of TB disease may be more than 100 times greater than for persons with TB infection alone. The burden of TB worldwide is emphasized by the fact that nearly $1 \%$ of the world's population is newly infected with TB each year. Nearly 3 million TB cases per year occur in south East Asia. Each year, more than 250,000 TB cases occur in Eastern Europe ${ }^{1,2}$. 
Tuberculosis is a global public health problem. No country in the world has succeeded in reaching the WHO point of control, that is "less than $1 \%$ tuberculin positive among the children of age $0-14$ year's age group. In Pakistan the survey report gave the prevalence rate of $54.7 \%$ while second survey report showed $54.4 \%$ based on tuberculin reaction of $10 \mathrm{~mm}+$. The yearly reported number of new cases of TB is 1.6 million including more than $2,50,000$ open cases according to the $6^{\text {th }}$ five year plan 1983-88 and 1,20,000 open cases according to the $8^{\text {th }}$ five year plan 1992-97. The morbidity rate is $1.8 \%{ }^{3}$.

Overall, one third of the world's population is infected with the TB bacillus, but not all infected individuals have clinical disease. The bacteria cause the disease when the immune system is weakened, as in older patients, in children and in patients who are HIV positive. The disease is more common in developing countries and among racial and ethnic minorities ${ }^{4,5}$. Gastro-intestinal tuberculosis is a major health problem in many underdeveloped countries. Autopsies of patients with pulmonary TB before the era of effective treatment demonstrated intestinal involvement in $55-90 \%$ of fatal cases. The previously noted frequent association between pulmonary TB and intestinal TB no longer prevails, and only a minority of patients (20-25\%) with abdominal TB now has had pulmonary $\mathrm{TB}^{3}$.

On gross pathologic examination, Gastro-intestinal TB can be classified into 3 categories: $(A)$ the ulcerative form of TB is seen in approximately $60 \%$ of patients. Multiple superficial ulcers largely confined to the epithelial surface. This is considered a highly active form of the disease with the long axis of the ulcers perpendicular to the long axis of the bowel. (B)The hypertrophic form is seen in approximately $10 \%$ of patients and consists of thickening of bowel wall with scarring, fibrosis and a mass like appearance. (C)The ulcerohypertrophic form is a subtype seen in $30 \%$ of patients. These patients have a combination of features of the ulcerative and hypertrophic forms ${ }^{10,11,12}$.

GI TB involves any part of the gut, although the ileum ${ }^{6,22}$ and colon ${ }^{19}$ are common sites. lleocecal involvement is seen in $80-90 \%$ of patients with $\mathrm{GI} \mathrm{TB}^{6}$. Nonspecific symptoms such as weight loss, fever, night sweats and abdominal pain are present in $80-90 \%$ of patients with intestinal TB. Nausea and vomiting may occur in patients with intestinal obstruction. Approximately one third of patients report constipation. Patients may present with right iliac fossa pain, or a palpable mass in the right iliac fossa. Hemorrhage and perforation are recognized complications of intestinal TB. Malabsorption may be caused by obstruction that leads to bacterial overgrowth (i.e. stagnant loop syndrome) $)^{6,7,8,9,10,15,18,21,22,25}$.

Early changes on barium examinations reveal nodular thickening of mucosal folds with loss of symmetry in fold pattern $^{6,7}$. Ulceration may be demonstrated on doublecontrast examinations, typically perpendicular to the long axis of the bowel; these heal with the formation of short annular strictures ${ }^{15,19}$. Because of persistent irritability from inflammation in the terminal ileum, rapid emptying of that segment may occur (Stierlin sign). The ileocecal angle is obliterated with a widely patent ileocecal valve. The ileum empties into a deformed cone-shaped caecum at right angles with hypertrophy of the ileocecal valve (Fleischner sign) $^{23,24}$. The CT features suggestive of abdominal TB include irregular soft-tissue densities in the omentum, low-attenuating masses surrounded by thick solid rims, low-attenuating necrotic nodes, disorganized appearance of soft-tissue densities, high-attenuating ascitic fluid and bowel loops forming poorly defined masses ${ }^{4,20,25}$. Laparoscopy with a targeted biopsy is currently considered the most rapid and specific method for diagnosing $\mathrm{GI} \mathrm{TB}^{5,14,16}$.

\section{PATIENTS \& METHOD}

It was an observational case series study which was conducted in surgical units, Bahawal Victoria Hospital, Bahawalpur during the period from 01-05-2005 to 30-042007. Total ninety six patients presented with abdominal tuberculosis. Patients of any age and both gender included in the study, who presented with abdominal symptoms \& signs and diagnosed as a case of abdominal tuberculosis. All those patients who did not have abdominal tuberculosis were excluded. The patients of abdominal tuberculosis were presented to surgical 
OPD as well as to emergency department. The patients were also referred from medical ward and chest ward. The clinical record of the patients was made on a Proforma. It included patient's biodata, symptoms \& signs, biopsy report, biochemical \& radiological report, treatment (surgery, chemotherapy) given and a follow-up. The diagnosis was made by histopathology of involved tissue like small gut, large gut or mesenteric lymph node. $X$-ray chest of all patients was done to rule out pulmonary tuberculosis. All patients of abdominal tuberculosis were operated and anti-tuberculosis chemotherapy was also given. Before commencing for the operation hemoglobin, fluid and electrolyte were corrected, naso-gastric aspiration and a broad spectrum antibiotics were given. The determining factor for choosing operative procedure were general condition of the patients, type of peritonitis, intestinal obstruction (acute or sub acute), the site and number of perforations in the gut. Postoperative care included nil by mouth, naso-gastric aspiration and intravenous fluid and broad spectrum antibiotic. Computer programmed SPSS was used for analysis.

\section{RESULT}

Total ninety six patients presented with abdominal tuberculosis during the period 01-05-2005 to 30-042007.Out of these 60(62.5\%) patients were male and $36(37.5 \%)$ were female. The male to female ratio was 5:3. The age ranges from 10 years to 60 years with the maximum patients $40(41.67 \%)$ falling in the age group 10 to 25 years and $30(31.25 \%)$ patients falling in the age group 45 to 60 years. Out of these 96 patients, $72(75 \%)$ belonged to low socio-economic group, 21(21.87\%) belonged to middle class and only $3(3.12 \%)$ belonged to high socio-economic group.

Out of these 96 patients, $28(29.16 \%)$ patients had concurrent pulmonary tuberculosis and was taking antituberculosis therapy. 15(15.63\%) patients were also taking anti-tuberculosis therapy for abdominal tuberculosis as advised by medical specialist. These patients were referred to surgical department because of repeated attack of intestinal obstruction or developed peritonitis. Remaining 53(55.21\%) patients came to surgical unit.
The clinical presentation of patients with abdominal tuberculosis was variable. $65(67.71 \%)$ patients presented in emergency department \& $31(32.3 \%)$ patients came in surgical OPD. 48(50\%) patients has signs \& symptoms of peritonitis and $20(20.83 \%)$ patients has sign \& symptoms of intestinal obstruction. sub-acute intestinal obstruction in 12(12.5\%) patients, mass right iliac fossa in $14(14.58 \%)$ patients, mass epigastrium in $2(2.08 \%)$ patients. Vague abdominal pain, loss of weight, low grade fever, signs \& symptoms of malabsorption were also present in most of these patients. Different clinical presentations of these patients are shown in table I.

All patients of abdominal tuberculosis had exploratory laparotomy. The operative finding were : perforation of small gut alone in $26(27.08 \%)$ patients, perforation proximal to a stricture of small gut in $20(20.83 \%)$ patients, stricture of small gut alone in $16(16.67 \%)$ patients, ileo-caecal mass in $14(14.58 \%$ ) patients, mass of transverse colon in $2(2.08 \%)$ patient, dense fibrous adhesions only in $10(10.42 \%)$ patients, pus \& mesenteric lymphadenopathy with no perforation of small gut in $8(8.33 \%)$ patients. The operative findings are given in table II.

\begin{tabular}{|l|c|c|c|}
\hline \multicolumn{4}{|c|}{ Table-I. Different clinical presentations of abdominal } \\
tuberculosis (n=96)
\end{tabular}

Different sites of gastrointestinal tract involved in abdominal tuberculosis in our study were: ilium in $30(31.25 \%)$ patients, jujenum in $20(20.83 \%)$ patients, ilium \& jujenum both in $12(12.5 \%)$ patients, ileo-caecal region in $14(14.58 \%)$ patients, transverse colon in 
$2(2.08 \%)$ patient, mesentric lymph node in $8(8.33 \%)$ patients and peritonium in $10(10.42 \%)$ patients. Different operative procedures done in these patients are given in table III.

\begin{tabular}{|c|c|c|}
\hline Operative findings & No. of pts & $\%$ age \\
\hline Perforation of small gut alone & 26 & $27.8 \%$ \\
\hline $\begin{array}{l}\text { Perforation of small gut proximal to } \\
\text { a stricture }\end{array}$ & 20 & $20.83 \%$ \\
\hline Stricture of small gut & 16 & $16.67 \%$ \\
\hline Ilio-caecal mass & 14 & $14.58 \%$ \\
\hline Peritoneal adhesions & 10 & $10.42 \%$ \\
\hline Mass transverse colon & 2 & $2.08 \%$ \\
\hline Mesenteric lymphadenopathy & 8 & $8.33 \%$ \\
\hline
\end{tabular}

\begin{tabular}{|l|c|c|}
\hline \multicolumn{3}{|c|}{$\begin{array}{c}\text { Table-III. Different sites of G I tract involved in abdominal } \\
\text { tuberculosis }(\mathbf{n = 9 6 )}\end{array}$} \\
\hline \multicolumn{1}{|c|}{ Sites of GI tract involved } & No. of $\mathrm{pts}$ & $\%$ age \\
\hline Ileum & 30 & $31.25 \%$ \\
\hline Jujenum & 20 & $20.83 \%$ \\
\hline Ileum \& Jujeum & 12 & $12.5 \%$ \\
\hline Ileo caecal region & 14 & $14.58 \%$ \\
\hline Transverse colon & 2 & $2.08 \%$ \\
\hline Peritoneum & 10 & $10.42 \%$ \\
\hline Mesentric lymph node & 8 & $8.33 \%$ \\
\hline
\end{tabular}

$56(58.33 \%)$ patients had uneventful recovery. Wound infection developed in $25(26.04 \%)$ patients, $8(8.33 \%)$ patients developed fecal fistula and wound dehiscence in $5(5.2 \%)$ patients. All these patients were given antituberculosis chemotherapy. Two patients of fecal fistula expired and mortality rate was $2.08 \%$.

\section{DISCUSSION}

The TB pathogen is Mycobacterium tuberculosis. Other mycobacterial species that simulate TB are Mycobacterium bovis, Mycobacterium avium, and Mycobacterium intracellulare. Routes of $\mathrm{GI}$ infection include the following: $(A)$ spread by means of the ingestion of infected sputum, in patients with active pulmonary TB and especially in patients with pulmonary cavitation and positive sputum smears;(B) spread through a hematogenous route from tuberculous focus in the lung to submucosal lymph nodes; and (C) local spread from surrounding organs involved by primary tuberculous infection (e g, renal TB causing fistulas into the duodenum or mediastinal TB lymphadenopathy involving the esophagus) $)^{3,17,23}$.

Pathologically GI TB is characterized by inflammation and fibrosis of the bowel wall and the regional lymph nodes, mucosal ulceration results from necrosis of Peyer patches, lymph follicles, and vascular thrombosis. At this stage of the disease, the changes are reversible and healing without scarring is possible ${ }^{6,7}$. As the disease progress, the ulceration becomes confluent and extensive fibrosis leads to bowel wall thickening, fibrosis, pseudotumoral and mass lesions. Strictures and fistula formation may occur. The serosal surface may show nodular masses of tubercles. Caseation may not always be seen in the granuloma, especially in the mucosa, but they are almost always seen in the regional lymph nodes $^{8,9,12,24}$.

In our study most patients infected with abdominal tuberculosis are of age group 10 to 25 years $40(41.67 \%)$, and 45 to 60 years $30(31.25 \%)$. This feature correlates with the literature that abdominal tuberculosis was common in younger and older age group patients. Male patients were infected more with tuberculosis than female patient $^{3,10,18}$. 72(75\%) patients belonged of low socioeconomic group in our study proving that abdominal tuberculosis is the disease low socio-economic group therefore better living standard \& nutrition play a most important part in protection against tuberculosis ${ }^{3,18}$. $28(29.16 \%)$ patients were taking anti-tuberculosis therapy for pulmonary tuberculosis and developed 
concurrent abdominal tuberculosis ${ }^{3}$.

Abdominal TB should be considered in the differential diagnosis for patients who present with non-specific abdominal complaints, weight loss over a long period and signs \& symptoms of malabsorption, and who originate from or have traveled recently to countries where TB is endemic $c^{6,8,9,15,20,21}$.The clinical presentations of abdominal tuberculosis were highly variable in our study. Peritonitis was the most common presentation in our study. Patients had complaints of abdominal pain, distention of abdomen, on \& of fever, tachycardia, tenderness in the abdomen, sign \& symptom of dehydration, constipation etc.

Peritonitis developed in abdominal tuberculosis either due to perforation of gut or tuberculous ascites became infected. ${ }^{10,18} 26(27.08 \%)$ patients of peritonitis had perforation of gut due to ulcerative type of tuberculous enteritis, $20(20.83 \%)$ patients of peritonitis had perforation of gut proximal to a stricture i.e. hypertrophic type of tuberculous enteritis and $4(\%)$ patients had pus in the peritoneal cavity with no perforation of gut.

The next common presentation was intestinal obstruction and it may be partial or complete with TB. Segmental involvement usually is in a stenotic form. The patients presented with abdominal pain (vague/colicky), abdominal distention and constipation. Sometimes patients did not pass the flatus. Sign \& symptoms of malabsorption were also present. Intestinal obstruction in abdominal tuberculosis develop due to stricture, mass formation and adhesion formation $4,7,11,22,23$. In our study stricture of small gut was found in $36(37.5 \%)$ patients, ileo-cecal mass in $14(14.58 \%)$ patients, and mass of transverse colon in $2(2.08 \%)$ patient and adhesion formation in 10(10.42\%) patients.

GI TB involves any part of the gut, although the ileum and colon are common sites. The ileum is more commonly involved than the jejunum. Ileo-cecal involvement is seen in $80-90 \%$ of patients with GI TB. This feature is attributed to the abundance of lymphoid tissue (Peyer patches) in the terminal ileum. Proximal small intestinal disease is seen more commonly with Mycobacterium avium-intracellulare (MAl) complex infection, predominantly one involving the jejunum ${ }^{10,17}$. The sites most commonly involved in abdominal tuberculosis in our study were ileum $30(31.25 \%)$. The other sites involved were jejunum $20(20.83 \%)$, both ileum \& jejunum 12(12.5\%),ileo-cecal region $14(14.58 \%)$,transverse colon 2(2.08\%), mesenteric lymphnode $8(8.33 \%)$ and peritonium only in $10(10.42 \%)$.According to the literature ileum, colon and jujenum were the common sites for gastro-intestinal tuberculosis in descending order ${ }^{6,11}$. But in our study two case of gastro-intestinal tuberculosis was reported in which colon was involved. This feature was in contrast to literature.

In patients with a relevant background history and clinical features suggestive of abdominal TB, laparoscopy is the investigation of choice with its advantage of histological confirmation. The measurement of ascitic fluid adenosine deaminase levels is a major advance in the diagnosis of tuberculous peritonitis ${ }^{5,14}$. The most common site of $\mathrm{GI}$ $T B$ is the ileocecal region, if the area can be reached with a flexible endoscope, a rapid diagnosis can be achieved if smear or culture results are positive or if caseating granulomas are seen in biopsy samples ${ }^{16,19}$.

In our study, the prognosis was good same as described in the literature. Two patients expired so the mortality rate was $2.08 \%$. The cause of death was anastomotic leakage leading to fecal fistula formation, septicemia and malnutrition etc. ${ }^{10,18}$.

Tuberculosis is an infective \& communicable disease so it is better to prevent its occurrence. Health education of the public in various aspects of prevention of tuberculosis. Non specific measures include control of drinking water, pasteurisation of milk, strict control of dairy workers, milk men, tuberculin testing of herds and destruction of all infective cows, sputum destruction, fly control, etc. Over crowding, unhygienic living condition, poor diet is avoided. The resistance of the population against tuberculosis can be increased by BCG vaccination and improved nutrition. For person closely 
exposed to active, open cavitary tuberculosis strict surveillance of close household contacts is recommended. Isoniazid $300 \mathrm{mg}$ daily for one year is recommended only in cases that can be closely monitored for the period of prophylaxis ${ }^{2,3}$.

\section{CONCLUSION}

Despite effective case finding and therapeutic tools and declines in morbidity \& mortality rates in some countries, tuberculosis appears to continue as an important communicable disease problem, word-wide for several decades to come. The chronic nature of the disease, the ability of the tubercle bacilli to remain alive in the human body for several years, the concentration of disease in the older age groups, the increased expectation of life, the high prevalence of infection rates in some countries, the relatively high reactivation rates, the emergence of drug resistant strains, association of tuberculosis \& HIVinfection and above all the perpetuation of the "nonspecific determinant" of the disease in the $3^{\text {rd }}$ world countries impede a rapid conquest of disease ${ }^{3}$.

In countries where Gastro-Intestinal Tuberculosis is endemic, a therapeutic trial of anti-tuberculosis treatment may be justified if the clinical picture is compatible with Tuberculosis ${ }^{2}$.

\section{REFERENCE}

1. World Health Organization: Tuberculosis. Fact sheet 104. 2000; Available at: http://www.who.int/inffs/en/fact104.html

2. WHO. Tuberculosis control and research strategies for the 1990's. Memorandum from a WHO-meeting. Bull WHO 1992; 70: 17

3. Iqbal yad, Abdullah Jan pathan. Communicable diseases of public health importance. In: Mohammad lliyas, Shah, Ansari. Community Medicine \& Public health. $6^{\text {th }}$ edition. Karachi :Time publisher, medical division, 2005: 867-879.

4. Yang ZG, Min $P Q$, Sone $S$, et al: Tuberculosis versus lymphomas in the abdominal lymph nodes: evaluation with contrast-enhanced CT. AJR Am J Roentgenol 1999 Mar; 172(3): 619-23.

5. Apaydin B, Paksoy M, Bilir M, Zengin K. Value of diagnostic laparoscopy in tuberculosis peritonitis. Eur J Surg1999; 165:158 -63.

6. Neil J.McC. Mortengen, Oliver Jones. The small intestine \& large intestine. In: RCG Russel, N..S.Williams, C.J.K.Bulstrode. Bailey \& Loves. Short practice of surgery. $24^{\text {th }}$ edition. London: Arnold, $2004: 1174$.

7. Jeremy Thompson. The peritoneum, Omentum, Mesentry \& Retroperitoneal space, In: RCG Russel, N.S.Williams, C.J...K.Bulstrode. Bailey \& Loves. Short practice of surgery. $24^{\text {th }}$ edition. London: Arnold , 2004 : 1143-44.

8. Badaoui E, Berney T, Kaiser L, Mentha G, Morel P. Surgical presentation of abdominal tuberculosis: a protean disease. Hepato-Gastroenterology 2000; $47: 751$. 5.

9. Goke MN, Leppert A, Flemming P: [Intestinal tuberculosis: Easier overlooked than diagnosed]. Z Gastroenterol 2001 Dec; 39(12): 1015-22.

10 al-Quorain AA, Facharzt, Satti MB: Abdominal tuberculosis in Saudi Arabia: a clinicopathological study of 65 cases. Am J Gastroenterol 1993 Jan; 88(1): $75-9$.

11. Marshall JB: Tuberculosis of the gastrointestinal tract and peritoneum. Am J Gastroenterol $1993 \mathrm{Jul}$; 88(7): 989-99.

12. Jadvar H, Mindelzun RE, Olcott EW, Levitt DB. Still the great mimicker: abdominal tuberculosis. Am J Roentgenol1997; 168:1455-60.

13. Haddad FS, Ghossain A, Sawaya E, Nelson AR. Abdominal tuberculosis. Dis Colon Rectum 1987; 30:724 -35 .

14. Semenovski AV, Barinov VS, Kochorova MN. Laparoscopy in the complex diagnosis of abdominal and genital tuberculosis. Problemy Tuberkuleza 1999; $3: 36-9$.

15. Tacyilcliz I, Akgun Y, Boylu S. Abdominal tuberculosis: diagnosis and surgical therapy in 139 cases. $\mathrm{Br} \mathrm{J}$ Surg1997; 84:92.

16. Tison C, de Kerviler B, Kahn X, Joubert M, Le Borgne J. Video-laparoscopic diagnosis and follow-up of a peritoneal tuberculosis. Ann Chirurg2000; 125:776 -8. 
17. Behr MA, Small PM. Molecular fingerprinting of Mycobacterium tuberculosis: how can it help the clinician? Clin Infect Dis ; 1997; 25: 806-810.

18. Sharma L, Gupta S, Soin AS: Generalized peritonitis in India--the tropical spectrum. Jpn J Surg 1991 May; 21(3): 272-7.

19. Das HS, Rathi P, Sawant P: Colonic tuberculosis: colonoscopic appearance and clinico-pathologic analysis. J Assoc Physicians India 2000 Jul; 48(7): 70810.

20. Jain R, Sawhney S, Bhargava DK, Berry M: Diagnosis of abdominal tuberculosis: sonographic findings in patients with early disease. AJR Am J Roentgenol 1995 Dec; 165(6): 1391-5.
21. Jakubowski A, Elwood RK, Enarson DA: Clinical features of abdominal tuberculosis. J Infect Dis 1988 Oct; 158(4): 687-92.

22. Teh LB, Ng HS, Ho MS, Ong YY. The varied manifestations of abdominal tuberculosis. Ann Acad Med Singapore 1987; 16:488 -94.

23. Wells AD, Northover JM, Howard ER. Abdominal tuberculosis: still a problem today. J R Soc Med1986; 79:149 -53.

24. Lambrianides AL, Ackroyd N, Shorey BA. Abdominal tuberculosis. Br J Surg1980; 67:887 -9.

25. Tacyilcliz I, Akgun Y, Boylu S. Abdominal tuberculosis: diagnosis and surgical therapy in 139 cases. $\mathrm{Br} \mathrm{J}$ Surg1997; 84:92.

\section{EXPERIENCE IS THE NAME EVERYONE GIVES TO THEIR MISTAKES.}

